\title{
9
}

\section{Free Will and Affirmation: Assessing Honderich's Third Way}

In the third and final part of his $A$ Theory of Determinism (1988), Ted 5 Honderich addresses the fundamental question concerning "the con- 6 sequences of determinism" (1988, II, 4). 'That is, what follows if 7 determinism is true? This question is, of course, intimately bound up 8 with the problem of free will and, in particular, with the question of 9 whether or not the truth of determinism is compatible or incompati- 10 ble with the sort of freedom that is supposed to be required for moral 11 responsibility. It is Honderich's aim to provide a solution to "the prob- 12 lem of the consequences of determinism," and a key element of this is 13 his attempt to collapse the familiar Compatibilist/Incompatibilist 14 dichotomy. More specifically, Honderich offers us a third way-the 15 response of "Affirmation" (2002, 125-126). Although his account of 16 Affirmation has application and relevance to issues and features beyond 17

\section{P. Russell $(\bowtie)$}

AU1 University of British Columbia, Vancouver, BC, Canada

University of Gothenburg, Gothenburg, Sweden

(C) The Author(s) 2017

G. Caruso (ed.), Ted Honderich on Consciousness, Determinism, and Humanity,

Philosophers in Depth, DOI 10.1007/978-3-319-66754-6_9 


\section{P. Russell}

freedom and responsibility, my primary concern in this chapter will be to examine Honderich's theory of "Affirmation" as it concerns the free will problem as it is generally understood.

\subsection{I}

The first part of Honderich's overall position in A Theory of Determinism is concerned with "the question of whether there does exist a conceptually satisfactory determinist theory of our lives" $(1988,4)$. The second part addresses the question of whether the theory as articulated in the first part and argues that it is well supported. The core of this theory, as Honderich interprets it, is expressed in these terms:

determinism is only a view of our own nature-in essence, the view that ordinary causation is true of us and our own lives, that in our choosing and deciding we are subject to causal laws. In this use of the word, determinism comes to no more that a yes answer to the question of whether we are in one fundamental way like plants or machines. Determinism in this sense does not include or imply an answer to the question of whether we are free or not. That question, maybe surprisingly, is left pretty well untouched. $(2002,3)$

The account of the theory of determinism is developed by Honderich largely in terms of a theory of causation and laws, along with an accompanying theory of mind and action. The theory of causation is one that holds that causes necessitate their effects, such that, given the occurrence of the former, whatever else happens, the latter will also occur $(2002,14-15)$. Causal relations and natural laws are understood as in terms of "regularities or as nomic connections" (2002, 15-16). Given this general account of causation, the question arises of whether or not "our lives are a matter of effects ... events that really have to happen because of earlier causal circumstances" $(2002,21)$. To answer this question, as it concerns our choices and actions, Honderich advances his theory of mind and action. 


\section{Free Will and Affirmation: Assessing Honderich's Third Way}

There are three basic elements to Honderich's account of mind and action. The first is what he calls Mind-Brain Determinism. This concerns the suggestion that each mental or conscious event, including choosing and deciding, is nomically related to neural events in such a way that the "neural event by itself or together with some other non-mental thing necessitated the mental one" $(2002,63)$. The second component is "Intuition Determinism," which maintains that nomically related neural and mental events have their causal origins in bodily (and environmental) events that involve no mental events. The third, and last, component in this general account of mind and action is "Action Determinism," which claims that each and every action is the effect of an "active intention," what is sometimes referred to as a volition or act of willing (2002, 59-60). The details of these three elements of Honderich's theory of mind and action involve, of course, a number of controversial issues but for our present purposes what matters is that they serve as the background set of proposals and assumptions that serve to articulate the general theory of determinism and bring us directly to the problem of the "consequences" (so interpreted). It is worth noting that Honderich does not assert simply "that determinism is true." What he claims is that it is "strongly supported, and that certainly it has not been shown to be false" (2002, 90 [original emphasis]). Honderich also allows that there may be some "micro-indeterminism" at the level of small particles it is "not amplified into indeterminism at the macro-level" $(2002,74-76)$. Even if microdeterminism is true, we are still left with strong support for the truth of a "macro-determinism" or "near-determinism" $(2002,90)$.

Throughout his account of a deterministic theory of mind and action, Honderich makes clear that there is an opposing view—namely, what he calls the "philosophy of Free Will," which presupposes the truth of indeterminism $(2002,2,4,35,41-42,49,69,76)$. What philosophers of 76 Free Will require is that responsible agents are originators of their actions. 77 If we are genuinely free, each of us must have "a kind of personal power 78 to originate choices and decisions and their actions" $(2002,2)$. It will not 79 suffice for us to be mere "initiators" of our actions in a manner that is 80 consistent with these events to be (necessitated) effects via a causal chain 81 or process $(2002,3)$. The guiding aim behind the idea of Free Will, 82 


\section{P. Russell}

Honderich argues, is that we need to understand responsibility in a certain way. What this requires, above all, is that we are "able now to choose differently from how we do, given the present and ourselves exactly as they are and the past exactly as it was" (2002, 41-42; and cp. 98, 109, 117). This form of absolute responsibility not only requires the falsity of determinism it also requires some sort of "ongoing entity" that possesses the "active power" required to produce or not produce a given action (2002, 42, 49). If we accept the truth of (near) determinism, then we must reject the idea of Free Will, so understood.

What is the significance of having to abandon or discard the idea of Free Will? Honderich analyses this issue within wider fabric of what he refers to as a set of "life-hopes." Life-hopes involve our attitudes to a range of features of the world that we care about, particularly as this concerns how our future activities may affect or influence how our lives unfold. In respect of these matters, we may be fortunate or unfortunate and, depending on this, we will feel a general attitude of a positive or negative kind. An attitude is an "evaluative thought" about something that we either approve or disapprove of. The question that presents itself in relation to determinism is, therefore, whether our life-hopes are in some relevant way threatened or damaged if the thesis of determinism is true.

It is with respect to this matter that the loss of Free Will is of some concern. The idea of Free Will, as we noted, involves a conception of ourselves as agents that are true originators of our actions. There is, Honderich maintains, a set of life-hopes that rests on this stronger conception of free agency $(2002,93,111-112)$. We want to be able not just to achieve success but to earn it and we want our achievements, whatever they are, to be more than just a causal product of our inherent nature and environment. While this is of importance to us if determinism is true, we do not have it $(2002,104)$. This situation will license an attitude of dismay about our predicament and circumstances so understood. It is for this reason, Honderich suggests, "that many people have found determinism to be a black thing" (2002, 95; and cp. 104).

Life-hopes are not, however, the only things that rest on the concept of freedom understood in terms of origination. Among other things that depend on this notion of initiated action as originated are certain attitudes or personal feelings to other people on the basis of their conduct toward us (e.g. resentment and gratitude). These personal feelings and reactions 


\section{Free Will and Affirmation: Assessing Honderich's Third Way}

are closely bound up with our moral feelings and responses_-an issue that 120 has been the primary focus of attention in the free will debate. What is crucial here is that the concept of freedom as originated action is essential to moral responsibility. The moral standing of an individual, on this account, rests on the assumption that they have not just acted voluntarily but possess the power to originate their actions and could have acted otherwise in the same circumstances. If these metaphysical foundations of agency are threatened, the whole fabric of morality will collapse, including our understanding of retributive justice and (deserved) punishment $(2002,101)$. Our sense of dismay, in face of the apparent truth of determinism, is felt most strongly in relation to this issue.

It is at this juncture that the split between Compatibilism and Incompatibilism becomes relevant. The analysis provided so far is one that turns on a concept of freedom (i.e. origination) that the incompatibilist embraces and endorses as the only true or genuine account of freedom that is relevant to these modes of concern. From the perspective of compatibilism, however, this entire analysis is mistaken. It is mistaken because what we really mean by freedom is a matter of voluntarinessnot origination $(2002,96,98)$. Free actions have a certain kind of causal history and are, as such, effects of a particular kind $(2002,96)$. When we secure a proper grasp of the concept of freedom, in terms of voluntariness, we can draw all the relevant distinctions we need concerning moral responsibility (2002, 98-99). There is, therefore, according to the compatibilist no conflict between freedom and responsibility and the truth of determinism. Even if determinism is true, nothing changes and nothing we have reason to care about is threatened. Instead of dismay, the attitude of the compatibilist is one of "satisfied intransigence" $(2002,97)$.

It is Honderich's central claim that neither of these approaches offers a satisfactory response to the likely truth of determinism. The oppositions we encounter between these two sides leave us in an unsatisfactory and unstable situation that demands a new response to determinism.

We need to get into a different way of feeling about determinism. We need 


\section{P. Russell}

156

157

158

159

160

161

162

163

164

165

166

167

168

169

170

171

172

173

174

175

176

177

178

179

180

181

182

183

184

185

186

187

188

189

Honderich's response to compatibilism and incompatibilism is that they are both mistaken. Both, moreover, are mistaken over several overlapping claims that they are agreed about. The first of these is that we possess some single, ordinary idea of freedom and that the alternative conception is either inadequate or incoherent (or both). The truth about our situation, Honderich maintains, is that we plainly have two distinct ideas of free choice and action and that both compatibilists and incompatibilists are wrong to dismiss the alternative view as irrelevant to our appreciation of the consequences of determinism. Any proposed solution along these lines will inevitably be one-sided and incomplete and will fail to identify properly the (inescapable) split we experience in our dual responses and attitudes (i.e. both dismay and intransigence).

Honderich argues that both parties in this debate mistakenly suppose "that the problem of the consequences can be settled by logical, intellectual, philosophical or linguistic means as traditionally conceived" (2002, 114) This approach, he suggests, over-intellectualizes the whole problem. The real problem is that we have two sets of attitudes, rooted in two sets of desires, and they issue in the divergent responses we have considereddismay and intransigence. Neither response, taken by itself, is entirely satisfactory. Compatibilist intransigence comes across as mere "bluff" and requires us to suppress and ignore the other side of the equation. On the other hand, simple dismay also ignores essential and inescapable features of ordinary life and our social experience. The relevant problem is how this "Attitudinarian instability and discomfort can be overcome and the two parties reconciled" (2002, 125-126).

Honderich's solution to this problem takes the form of what he calls "Affirmation" $(2002,126)$. What this requires is that, assuming the truth of determinism, we must

try to give up whatever depends on thoughts inconsistent with it. Above all we have to try to accept the defeat of certain desires. This is bound up with trying to be happier about, or more reconciled to, the desires in which we can persist, the ones consistent with determinism. $(2002,125)$

This means in the first place, in accepting that "our attitudes involving voluntariness cannot really allow us to be intransigent." If determinism is 


\section{Free Will and Affirmation: Assessing Honderich's Third Way}

true, we cannot claim that "nothing changes" and that this "leaves things 190 just as they are" $(2002,97,99,125)$. At the same time, making these 191 concessions "need not give rise to dismay, taking everything as wrecked" 192 (2002, 125). By this route we achieve some balance between dismay and 193 intransigence, whereby we recognize and accept that some things impor- 194 tant to us are discredited or lost, to the extent that they are based on 195 assumptions about origination, but that there is also a great deal that we 196 care about and that which matters to us remains untouched and survives. 197

Honderich summarizes his account of Affirmation as follows:

198

To put the proposal in a nutshell, our new response should be this: trying 199 by various strategies to accommodate ourselves to the situation we find ourselves 200 in-accommodate ourselves to just what we can really possess if determinism is 201 true, accommodate ourselves to the part of our lives that does not rest on the 202 illusion of Free Will. We can reflect on what is perhaps the limited worth of 203 what we have to give up, consider the possible compensations of a belief in 204 determinism, take care not to underestimate what we can have, and consider a certain prospect having to do with genuine and settled belief in determinism. (2002, 126 [emphasis in original])

To embrace this response of "Affirrmation" is, Honderich suggests, to 208 adopt "a philosophy of life," one which consists in feelings that provide 209 us with some support and as much satisfaction as the truth will allow. 210 Although Affirmation rejects all forms or reliance on illusions of any 211 kind, it nevertheless rejects any (pessimistic) suggestion that determinism 212 leaves us "defeated" or without any substantial and significant sources of 213 consolation. This is not just a matter of "putting a good face on things" 214 but of recognizing gains as well as losses that come with the belief in 215 determinism $(2002,131)$. Among the gains is that we are in a position to 216 withdraw from retributive sentiments and practices that are grounded in 217 our illusory belief in Free Will. This is all achievable without the world 218 going "cold," or leaving no scope for personal emotions and feelings, or 219 losing all sense of achievement and meaning (see Pereboom 2001, 2013, 220 2014). The upshot of all this is that the response of Affirmation is one 221 that rejects undiluted "dismay" or "intransigence" but offers, instead, a 222 blend or mix that avoids the one-sided, monochromatic alternatives that 223 have generally been advanced. 


\section{P. Russell}

226

227

228

229

230

231

232

233

234

235

236

237

238

239

240

241

242

243

244

245

246

247

248

249

250

251

252

253

254

255

256

257

258

Having reviewed the essential features of Honderich's theory of "Affirmation," we can now ask if this is indeed, as Honderich claims, the solution we have been seeking for "the problem of the consequences of determinism" $(2002,133)$. The short answer to this—as with the theory itself-is in some ways "Yes" and, in other ways, "No." Let us begin with what seems to be right and illuminating about "Affirmation." The best way to appreciate the significance of Affirmation is by locating it within the matrix of other available positions on offer. Affirmation is one of several positions on this subject that involve significant modifications and amendments to the more familiar classical accounts. (As Honderich points out, neither the Compatibilist or Incompatibilist tradition is "absolutely uniform" $(2002,110)$.) Although several of these theories contain overlapping or common elements, each takes a different turn on some key issues — and Affirmation needs to be distinguished from them in respect of these elements.

Affirmation is most obviously opposed to the idea of Free Will, understood in terms of the form of origination that libertarians seek to secure. In this respect, Determinism and Affirmation plainly imply skepticism about the metaphysics of libertarian agency-which is, according to Affirmation, a persisting source of dismay. However, although Affirmation is skeptical about Free Will and origination, it rejects complete, global skepticism about freedom and responsibility. The reason for this is that it rejects the suggestion that origination is our (sole) true idea of freedom. According to Affirmation, voluntariness serves as one kind of freedom and provides a basis for surviving credible forms of responsibility based upon it. It follows from this that any unqualified form of dismay or pessimism cannot be supported or sustained, simply because origination is incompatible with the truth of determinism. Affirmation, therefore, rejects "incompatibilist" arguments about freedom and responsibility, and any unqualified pessimism that it may be taken to license on the ground that they fail to accommodate the dual nature of our concepts of freedom and responsibility (see, e.g. Strawson 1994). 


\section{Free Will and Affirmation: Assessing Honderich's Third Way}

Not all skeptics about freedom and moral responsibility take themselves to be committed to dismay or pessimism as a metaphysical attitude that flows from the truth of determinism. An important recent development in the free will debate has been an effort, by Derk Pereboom, Gregg Caruso and others, to defend "Hard Incompatibilism" or "Optimistic Skepticism," which holds that the only form of freedom that grounds desert-based theories of responsibility is origination and that, although this is impossible, no deep or unqualified pessimism flows from this. On the contrary, there are, they claim, significant benefits to this skeptical outlook (see, e.g. Pereboom 2001; Waller 2011; Caruso, forthcoming). There are certainly some important affinities between Honderich's Affirmation and "Hard Incompatibilism," but, as Honderich shows, there remain important points of divergence $(2002,143)$. One aspect of this is that Affirmation remains firmly committed to the stance of dismay (or pessimism) — rooted in skepticism about the idea of Free Will—which is a stance that Hard Incompatibilism aims to discredit or minimize. The crucial point here is that Affirmation refuses to deny the source of dismay that determinism generates, as grounded in skepticism about the (Incompatibilist) idea of Free Will or origination.

One further theory that we should consider in this context is "Illusion," as advanced and defended by Saul Smilansky (2000, 36-38). As with Hard Incompatibilism, Smilansky's "Illusionism" bears some family 276 277 resemblance to Affirmation. One important feature they share is a "dualist" view about the nature of freedom and responsibility, which denies that we have just one conception which renders either Compatibilism or Incompatibilism true or false. Where they diverge, however, is that "Illusionism" takes the importance of origination to be so deep and pervasive in our ethical lives that for practical reasons we should encourage and promote belief in origination-even if we have some theoretical reason for doubting it (e.g. evidence of the truth of determinism). For Illusionism, the truth of determinism and abandoning the idea of free will would be so catastrophic and disastrous for our ethical and social lives that we must reject any option or theory that would encourage skepticism about the idea of Free Will. This is a view that Honderich, explicitly rejects. The philosophy of life that Affirmation embraces insists that the 


\section{P. Russell}

path of Illusion is neither necessary nor desirable and that Affirmation secures all that is needed to sustain and support a worthwhile life and a viable ethical community $(2002,126,131-132)$.

Where does this taxonomy of Affirmation in relation to other alternative views leave us? In my view, Affirmation not only presents a distinctive stance and position on this issue, on all the points and issues that separate it from its alternatives mentioned above, it generally takes the right view. Affirmation is correct, for example, to reject "Monism" about the concept of freedom as it concerns moral responsibility. Related to this, it is right to reject any unqualified skepticism about freedom and responsibility, along with any unqualified pessimism or dismay that may be based on it. Finally, I would also agree that Affirmation is right to repudiate "Illusionism" as a way of dealing with the "probable" truth of determinism, insist instead on being truthful about our human predicament. In several respects Affirmation shares some of the key merits and strengths in P.F. Strawson's influential contribution to this topic in his paper "Freedom and Resentment." Along with Strawson, Affirmation places emphasis on moral sentiments or reactive attitudes in accounting for moral responsibility. Both aim to "reconcile" the main parties in this dispute by means of accepting some of their claims and not others and present a position that gives us a recognizable picture of human agents as part of the natural world. However, what does separate Affirmation from Strawson's theory is that it does not claim to "leave things just as they are" $(2002,99)$. Affirmation insists on recognizing the real losses, as well as the gains, that come with this philosophy of life $(2002,126,131)$. In all these respects, so it seems to me, Affirmation is firmly on the right track and highly illuminating.

Having indicated what makes Affirmation distinctive, illuminating, and credible, let me now consider some other important matters in respect of which it is less convincing. In order to do this, I want to compare Affirmation with another perspective on the free will problem-a view I will call Free Will Pessimism (Russell 2017a). The label Free Will Pessimism does not involve a metaphysical attitude that is based on some form of free will skepticism. On the contrary, whereas free will skepticism is the view that our vulnerability to conditions of fate and luck serve to discredit our view of ourselves as full and responsible agents 


\section{Free Will and Affirmation: Assessing Honderich's Third Way}

(e.g. as implied by the truth of determinism), Free Will Pessimism rejects free will skepticism. The basis of its pessimism rests with the assumption that we are free and responsible agents who are, nevertheless, subject to fate and luck. According to Free Will Pessimism, all the major parties and positions in free will debate (both Compatibilists and Incompatibilists) are committed to modes of evasion and distortion regarding our human predicament in respect of agency and moral life. The question that arises, therefore, is whether or not the "dualism" involved in Affirmation, in respect of both its understanding of two concepts of freedom and the associated split in our metaphysical attitudes, effectively identifies and overcomes these modes of evasion?

In order to describe the alternative picture that Free Will Pessimism presents of the free will problem as it relates to the consequences of determinism, we need to consider, first, the core incompatibilist argument against all compatibilist strategies and proposals. Let us call this incompatibilist argument the Basic Exclusion Argument (BEA):

1. There is a set of conditions $\varphi$ (under some contested interpretation) 346 such that an agent is free and responsible for an action or set of actions when these conditions are satisfied.

2. There is another set of conditions $\beta$ (under some contested interpretation) such that an agent's action or set of actions are subject to fate and luck when those conditions are satisfied.

3. Any action (or set of actions) that satisfy $\varphi$ cannot be such that it also 351 satisfies $\beta$. That is to say, if an action $\mathrm{X}$ satisfies $\varphi$ it cannot also be subject to $\beta$. $<$ Exclusion Premise $(E P)>$.

4. Any and all compatibilist interpretations of $\varphi$ are such that they may 354 be satisfied and still be subject to $\beta$ (i.e. compatibilist conditions $\varphi^{*}$ do not support or satisfy EP/ \#3 above).

5. It follows that we must reject any and all compatibilist interpretations $\varphi^{*}$, as they are inadequate as judged by a standard that compatibilists do not and cannot reject (EP).

Libertarians believe that their own interpretation of conditions $\varphi$ can 362 satisfy EP and avoid the skeptical conclusion, although this requires the 


\section{P. Russell}

364

365

366

367

368

369

370

371

372

373

374

375

376

377

378

379

380

381

382

383

384

385

386

387

388

389

390

391

392

393

394

395

396

397

398

399

falsity of determinism. Skeptics maintain that there is no avoidable set of conditions $\varphi$ that serve to satisfy EP and, hence, the skeptical conclusion goes through either way-whether determinism is true or false.

Proponents of BEA are entirely justified in claiming that compatibilists have consistently adhered to EP and aimed to satisfy it. What compatibilists have denied is premise \#4, the claim that compatibilism fails to satisfy the standard set by EP (premise \#3). Let us consider, then, the classical compatibilist argument that is launched against premise \#4, an argument aiming to show that agents who satisfy suitably interpreted compatibilist conditions $\left(\varphi^{*}\right)$ are not subject to fate and luck (i.e. conditions $\beta$ ). The core feature of this argument is that the incompatibilist claim (premise \#4) relies on a basic confusion between fatalism and determinism. More specifically, if we properly interpret conditions $\beta$ (i.e. as conditions $\beta^{*}$ ), then premise \#4 is groundless. Fatalism is the doctrine that all our deliberations and actions are causally ineffective and make no difference but nothing about the thesis of determinism implies that this is the universal condition (see, e.g. Ayer 1954, 22-23; and especially Dennett 1984, 104-105, 129).

This line of response, aimed at refuting premise \#4, may be found doubly unconvincing. First, appealing to this distinction between determinism and fatalism is a shallow and evasive understanding of incompatibilist concerns. The relevant issue is not about the causal influence of the agent but rather the causal influence on the agent. On the assumption of determinism, however complex the mechanisms or capacities involved, the ultimate source or origin of conduct and character is external to the agent and not within the agent's control or influence. For this reason, we need to distinguish "contributory fatalism," which concerns the universal causal impotence of agents, from "origination fatalism," which concerns the causal source or origins of an agent's conduct and character and the limits of control over this. Whereas determinism does not imply universal contributory fatalism, it does imply universal origination fatalismand it is this that is found particularly troubling (Russell 2000, 2017a). ${ }^{3}$

The second objection flows from the first. Given the issue of origination fatalism and the limits of control over conduct and character, as generated on compatibilist models, we run directly into worries about moral luck. The general worry here is about agents being subject to moral 


\section{Free Will and Affirmation: Assessing Honderich's Third Way}

evaluation (i.e. reactive attitudes etc.) in ways that are sensitive to factors 400 they do not control (Nagel 1976). Granted that it is intuitively unjust to 401 hold agents responsible for aspects of their conduct and character that 402 they do not control (as per EP, premise \#3), conditions of freedom and 403 responsibility cannot be sustained in these circumstances where an agent 404 is subject to fate and luck along the lines described. The familiar compati- 405 bilist line of response to this, consistent with much contemporary com- 406 patibilist thinking, is that human agents are "not just lucky," we are 407 "skilled self-controllers" (Dennett 1984, 94). Once again, however, this 408 general line of reply seems not to engage with the real force or basis of 409 incompatibilist concern. Incompatibilists recognize, of course, that com- 410 patibilist accounts of self-control and reason-responsiveness do not 411 leave us "merely lucky" or unskilled, unable to enhance our abilities and 412 talents. The point is, rather, that the specific capacities we have, the way 413 we actually exercise them, and the occasions we are provided for employ- 414 ing them, all depend, given deterministic assumptions, on external factors and conditions no agent ultimately has control over.

On this account, the free will problem, as generally understood, turns on the assumption that EP is correct and that the most effective compatibilist strategy depends on refuting premise \#4. Incompatibilists claim that this cannot be done and that determinism implies skepticism about freedom and responsibility. There is, however, an alternative strategy we may call "Critical Compatibilism." Critical Compatibilism accepts premise \#4 and agrees with incompatibilists that orthodox compatibilist attempts to refute are shallow and evasive and, as such, fail. At the same time, critical compatibilists reject the skeptical conclusion because they reject EP/ premise \#3. According to Critical Compatibilism, any plausible form of compatibilism must recognize and acknowledge the influence of fate and luck on the manner and context in which our capacities of rational selfcontrol operate. In taking this view, critical compatibilism maintains that any plausible form of compatibilism must accept Free Will Pessimism, which allows that free and responsible agents may still be subject to significant forms of fate and luck (contrary to the requirements of EP).

An important feature of Critical Compatibilism is the particular set of metaphysical attitudes that this stance naturally licenses or occasions. In circumstances where EP is not satisfied, we have (deep) reasons for being 


\section{P. Russell}

436

437

438

439

440

441

442

443

444

445

446

447

448

449

450

451

452

453

454

455

456

457

458

459

460

461

462

463

464

465

466

467

468

469

470

471

472

"troubled" or "disconcerted" by our predicament as this relates to human ethical life and moral agency. Even if we are "fortunate" in this particular ethical trajectory our lives may take, there is no basis-as incompatibilists rightly insist-for an easy optimism when fate and luck intrude into our ethical lives and the way we may exercise our moral agency. The crucial point, in relation to Critical Compatibilism, is that a pessimism (or sense of "dismay") of this nature is not rooted or grounded in skepticism about free will and moral responsibility. On the contrary, it presupposes that we reject any skepticism of this kind, since the form of pessimism that is occasioned depends on viewing ourselves and others as agents who are free and responsible but, nevertheless, subject to fate and luck in the exercise and operation of our moral capacities.

With this understanding of the central features of Free Will Pessimism in place, we may now turn back to Affirmation and ask where it stands in relation to Free Will Pessimism? We can begin by asking, more specifically, where Affirmation stands on the issue of whether to accept or reject EP (premise \#3 of BEA)? Clearly, Affirmation may go in one or other of two directions. Affirmation may be interpreted - and, on the face of it, is most plausibly interpreted - as offering a "dualist" response to EP which holds that it is both satisfied and not satisfied, depending from which side of the Compatibilist/Incompatibilist fence we are viewing it. Given the truth of Determinism and the consequent impossibility of origination or Free Will, Affirmation will agree with Incompatibilists that EP cannot be satisfied in terms of this concept - and this will license our sense of dismay based on skepticism about freedom and moral responsibility (as suggested by BEA). This is, however, only one side of the mixed dualism of Affirmation. Since we have another concept of freedom, understood in terms of voluntarism, which allows for a different set of implications relative to freedom and responsibility, EP may be satisfied by the relevant set of Compatibilist standards. This is the case, if we accept the orthodox compatibilist project, which turns on a refutation of premise \#4 (and an acceptance of EP).

If Affirmation is interpreted in the manner described above, then neither of its dualist components involves rejecting or discrediting EP and embracing any form of Free Will Pessimism. The Incompatibilist side holds that EP cannot be satisfied but must be respected (hence the skeptical conclusion follows). The Compatibilist side holds that EP can 


\section{Free Will and Affirmation: Assessing Honderich's Third Way}

be satisfied, as long as we do not conflate modes of freedom and responsibility secured by voluntariness with those that are based on origination or Free Will. According to Affirmation, both these views can be held together, without contradiction. The two views, along with their accompanying set of attitudes, can be simultaneously held and are insulated from each other because both rest on ideas and concepts that are equally firmly rooted in ordinary life. For this reason, given the truth of Determinism, our reflections about EP will generate a measure of both dismay and intransigence-such that the truth of Determinism neither leaves our lives in ruins nor leaves everything unchanged and where it was. The crucial point remains, however, that although dismay attaches to the loss of origination, it does not generate any form of Free Will Pessimism, since, on both sides, Affirmation remains committed to respecting EP (if not satisfying it). Affirmation, so interpreted, denies the very possibility of Free Will Pessimism (i.e. it accepts EP as it appears in BEA). Another way of putting this point is that, along with the orthodox Compatibilist, Affirmation holds that Compatibilists should hold onto EP but reject premise number \#4, which claims that Compatibilist conditions may be satisfied while agents are still subject to fate and luck. The Compatibilist element of Affirmation is, on this account, orthodox and not Critical Compatibilist in content. Like other views in the free will debate, Affirmation does not take the step taken by Critical Compatibilists and Free Will Pessimism, which involves discarding the entire ambition of satisfying EP or to find a "solution" conceived in these terms.

Although Affirmation may be interpreted in these terms, it is unsettled and open-ended enough, in relation to these matters, that another interpretation is available to it. Affirmation may accept, with Critical Compatibilism, that any plausible and credible form of Compatibilism must accept and embrace Free Will Pessimism. That is to say, the Compatibilist component of Affirmation would not only reject simple intransigence because Determinism implies skepticism about origination and the idea of Free Will, but also because Compatibilism, understood in terms of freedom and moral responsibility based on voluntarist views, has its own independent sources of pessimism. This distinct and independent source of pessimism is the claim that free and responsible agents (in Compatibilist terms) are still subject to significant modes of fate and

473 474 475 476 477 478 479 480 481 482 483 484 485 486 487 488 489 490 491 492 493 494 495 496 497 498 499 500 501 502 503 504 505 506 507 508 509 


\section{P. Russell}

510

511

512

513

514

515

516

517

518

519

520

521

522

523

524

525

526

527

528

529

530

531

532

533

534

535

536

537

538

539

540

541

542

543

544

545

luck. All orthodox Compatibilist efforts to dismiss this (via refutations of premise \#4) are rejected as themselves evasive and shallow responses to a more truthful account of the human predicament. On this interpretation, therefore, there is nothing about Affirmation that precludes it from endorsing Free Will Pessimism. The difficulty with Affirmation, as presented, is that despite its other insights, it fails to provide a clear assessment of these issues relating to EP and Free Will Pessimism, leaving its Compatibilist component indeterminate with respect to these important matters.

One reason why these matters are of such importance is that the sort of "solution" we are looking for here depends on how we understand the problem of Determinism in relation to the free will problem. Honderich presents Affirmation as a solution to the problem of Determinism based on its dual "Attitudinarian" components (2002, 104, 120-121, 122, 126, 133). He presents Affirmation as restoring a kind of balance and stability in our divergent and contrary responses to the truth of Determinism and as providing us with a "philosophy of life" that allows us to recognize and accept certain losses while retaining sufficient resources to carry on with some comfort and confidence. The difficulty we are faced with, however, is to identify carefully and precisely the relevant persisting sources of dismay or pessimism and how exactly they relate to the Compatibilist side of Affirmation. As presented, Honderich's account seems to locate all relevant sources of dismay with the loss of origination. If the Critical Compatibilist is correct, this is a mistaken and inadequate analysis of the problem. It is not just that we cannot satisfy the aim and aspirations of EP in Incompatibilist terms but that we need to discard EP altogether as a standard for an acceptable solution to the freewill problem (a matter which even the skeptic is mistaken about). The cost of rejecting or discarding EP as a basic assumption for assessing proposed "solutions" to the free will problem is that we must allow that free, responsible agents are still subject to fate and luck — and this is something that is independently disturbing and troubling and plainly cannot be based on any general skepticism about freedom and responsibility. If Affirmation embraces Free Will Pessimism, then it must abandon any suggestion that it is a "solution" to the free will problem conceived in terms of the ambition to satisfy EP on some relevant interpretation. The Free Will Pessimist claims that what we have here is not a (puzzling) problem to be solved, but a 


\section{Free Will and Affirmation: Assessing Honderich's Third Way}

troubling predicament to be acknowledged. All the major parties in the 546 free will debate-including orthodox Compatibilists-are resistant to 547 the suggestion that free, responsible agents may still be subject to signifi- 548 cant modes of fate and luck. What still needs to be clarified, however, is 549 where Affirmation stands on this matter.

The foregoing problem is indicative of weaknesses in Affirmation's commitment to the two concepts/two attitudes formula at the heart of its analysis. The split between Compatibilism and Incompatibilism that serves as the framework of its analysis conceals what all the traditional parties share-namely, a commitment to standards of freedom and responsibility that satisfy EP. As we have noted, even the skeptic shares this standard, taking the view that EP must be respected, even if it cannot be satisfied. It is this more fundamental conception that is the real obstacle, not just for understanding the consequences of the truth of Determinism, but for understanding the truth about the human predicament with respect to agency, whether (near) Determinism is true or not. The question we need to ask, at this juncture, is why have compatibilists been so reluctant to embrace critical compatibilism and Free Will Pessimism? I have provided a more extended answer to this question elsewhere, but for now a brief summary will suffice (Russell 2017a). What is it about EP that orthodox compatibilists find so difficult to abandon? There are, I suggest, two considerations that run deep in orthodox compatibilist thinking that account for this resistance to jettisoning EP. The first concerns the relationship between the exclusion premise and "the morality system" and the second, related to the first, concerns the question of optimism.

With respect to the first point, the exclusion premise may be understood as an essential feature of what Bernard Williams calls "the morality 550 551 552 553 554 555 556 557 558 559 560 561 562 563 564 565 566 567 568 569 570 571 572 573 system" (1985, Ch. 10). Among the various distinguishing features of 574 "the morality system" is its insistence that moral responsibility, rightly 575 understood, must somehow be capable of "transcending luck," provid576 ing a purity that only genuine "rational" agency of some kind makes possible (Williams 1985, 217; see also Nagel 1976). Although orthodox Compatibilists resist the aspirations of libertarians to secure some form of absolute or ultimate agency (qua origination), they remain committed to the particular conception of responsibility encouraged by the 
582 morality system and believe that it can be satisfied within compatibilist 583 constraints (see, e.g. Wallace 1994, 39, 64-66). It is these aims and aspi584 rations that Critical Compatibilism rejects. The trouble with Affirmation, 585 from this point of view, is that, on the face of it, it simply absorbs or 586 incorporates the orthodox Compatibilist aims and assumptions of the morality system into its own proposed "solution" to the problem. If this is the case, then both components or dimensions of Affirmation theory retain the problematic baggage of "the morality system" and its peculiar aims and assumptions.

The second point is intimately concerned with the first. A further feature of "the morality system" is its aspiration to secure optimism of a certain kind-a comforting and consoling picture about our ethical lives and predicament. This feature of "the morality system" is deeply resistant to any account that suggests that the exercise and operation of our moral and rational capacities depends on large measure on factors that are not controlled or governed by those same capacities and powers. All the parties in the freewill debate-libertarians, compatibilists, and skeptics alike-hold onto EP and the particular form of optimism that it insists on. This form of optimism denies the very possibility of Free Will Pessimism, much less accepts it as the truth about our human predicament.

We may, in light of the above, ask to what extent Affirmation remains 604 committed to this form of optimism as secured by an adherence and commitment to EP? It is certainly evident that, unlike orthodox Compatabilism or libertarianism, Affirmation dispenses with any pure or simple optimism. It insists, more specifically, on the need to accommodate "dismay" as having a secure foothold, given the truth of Determinism. However, as has also been explained, this form of dismay is grounded entirely in skepticism and the origination of free will. Retaining this form of dismay is consistent with remaining committed to an optimism that rejects the very possibility of Free Will Pessimism (e.g. the skeptic may be pessimistic because EP cannot be satisfied but will not allow that EP should be discarded or abandoned altogether). As things stand, it is not clear whether Affirmation is able or willing to accommodate forms of dismay or pessimism based on rejecting EP and the associated aims and aspirations of the morality system. 


\section{Free Will and Affirmation: Assessing Honderich's Third Way}

Let me conclude by describing an analogy that may help us to 618 appreciate both the strengths and weaknesses of Affirmation. There is an 619 aspect of Affirmation that we may think of in terms of the Duck/Rabbit 620 Gestalt switch. It is a basic feature of Honderich's overall argument that a 621 single image is not the whole truth on this topic. To insist on one side or 622 the other as having the whole truth, and the other as being mistaken, is 623 an error that both compatibilists and Incompatibilists share. We can and 624 should, it is argued, accommodate and reconcile the partial truth con- 625 tained in each perspective or position. We can, as it were, reconcile the 626

view of the Incompatibilist Duck with that of the Compatibilist Rabbit, 627 as long as we do not insist on the sole truth of either. Despite its attractions, however, this reconciliation project has its own vulnerabilities. More specifically, if Free Will Pessimism is right, both the Compatibilist and Incompatibilist components that are absorbed by Affirmation share a deeper and more problematic set of assumptions about the nature and conditions of freedom and moral responsibility. The aims and assumptions in question are those that are encouraged and endorsed by "the morality system." It may be that Affirmation can distance itself from these shared aims and assumptions but, as presented, it does not do this and, to this extent, it fails to identify the deeper difficulties that present themselves with respect to the consequences of Determinism and its relevance to the freewill problem as generally understood. ${ }^{4}$

628

629

630

631

632

633

634

635

636

637

638

639

\section{Notes}

1. My discussion in this chapter focuses largely on Honderich (2002), which, although it "follows the same path" as the earlier work, is intended to be more than a mere précis of it. As Honderich points out, How Free Are You? is not only shorter and more recent, it advances some new lines of argument and interest $(2002,6-7)$. For all these reasons, it seems the best work to focus my attention on for the purpose of this chapter-but readers should also consult Honderich's first and larger work for more detailed arguments and discussions relating to his views.

641

642

643

644

645

646

647

648

2. There are several overlapping features of Honderich's approach here 649 that run parallel to P.F. Strawson's famous contribution in "Freedom

650 


\section{P. Russell}

and Resentment" (1962). This includes the importance of not "overintellectualizing" this issue and, related to this, an understanding of this debate in terms of broadly optimistic and pessimistic metaphysical attitudes.

3. Whether we attach the label "fate" to this concern is merely a verbal matter- the substantial concern or issue remains with us.

4. It may be argued that Honderich's commitment to a dualist picture of our conceptual commitment and metaphysical attitudes requires a richer genealogical approach—one that is more sensitive to how we (modern, Westerners) have acquired the aims and assumptions of "the morality system" and its specific views about moral freedom and ethical life. This is certainly one feature that divides Honderich's (ahistorical) approach from William's more self-conscious genealogical account. See, in particular, Williams (1993).

\section{References}

Ayer, A. J. 1954. Freedom and necessity. Reprinted in Free will, ed. Gary Watson, 15-23. Oxford: Oxford University Press.

Caruso, Gregg D. forthcoming. Free will skepticism and its implications: An argument for optimism. In Free will skepticism in law and society, ed. Elizabeth Shaw and Derk Pereboom. Cambridge, MA: Cambridge University Press.

Dennett, Daniel. 1984. Elbow room: The varieties of free will worth wanting. Oxford: Clarendon Press.

Honderich, Ted. 1988. A theory of determinism: The mind, neuroscience and life hopes. Oxford: Oxford University Press.

2002. How free are you? Oxford: Oxford University Press.

Nagel, Thomas. 1976. Moral luck. Reprinted in The philosophy of free will: Essential readings from the contemporary debates, eds. Paul Russell and Oisin Deery, 31-42. New York: Oxford University Press.

Pereboom, Derk. 2001. Living without free will. Cambridge, MA: Cambridge University Press.

- 2013. Optimistic skepticism about free will. In The philosophy of free will: Essential readings from the contemporary debates, ed. Paul Russell and Oisin Deery, 421-449. New York: Oxford University Press.

-2014. Free will, agency, and meaning in life. Oxford: Oxford University Press. 


\section{Free Will and Affirmation: Assessing Honderich's Third Way}

Russell, Paul. 2000. Compatibilist fatalism. Reprinted in The philosophy of free 686 will: Essential readings from the contemporary debates, eds. Paul Russell and 687 Oisin Deery, 450-468. New York: Oxford University Press. 688

- 2002. Pessimists, pollyannas and the new compatibilism. In The Oxford 689 handbook of free will, ed. Robert Kane, 229-256. New York: Oxford 690 University Press.

691

2017a. Free will pessimism. In Oxford studies in agency and responsibil- 692 ity, vol. 4, ed. David Shoemaker. Oxford: Oxford University Press. Reprinted 693 in Russell (2017b).

694

. 2017b. The limits of free will: Selected essays. New York: Oxford University Press.

695

Russell, Paul, and Oisin Deery, eds. 2013. The philosophy of free will: Essential 696 readings from the contemporary debates. New York: Oxford University Press.

Smilansky, Saul. 2000. Free will and illusion. Oxford: Oxford University Press.

Strawson, Peter F. 1962. Freedom and resentment. Reprinted in The Philosophy of free will: Essential readings from the contemporary debates, eds. Paul Russell and Oisin Deery, 63-83. New York: Oxford University Press.

697 698 699 700 701 Strawson, Galen. 1994. The impossibility of ultimate moral responsibility. 702 Reprinted in The philosophy of free will: Essential readings from the contemporary debates, eds. Paul Russell and Oisin Deery, 363-378. New York: Oxford University Press.

703 704 705 706

Wallace, R. Jay. 1994. Responsibility and the moral sentiments. Cambridge, MA: 707 Harvard University Press. 708

Waller, Bruce. 2011. Against moral responsibility. Cambridge, MA: MIT Press. 709 Watson, Gary, ed. 1982. Free will. Oxford: Oxford University Press. 710 Williams, Bernard. 1985a. Ethics and the limits of philosophy. With a commen- 711 tary by A.W. Moore and a foreword by Jonathan Lear. Routledge: London 712 and New York: Routledge Classics (edition 2011). 713

- 1985b. How free does the will need to be?. Reprinted Making sense of 714 humanity, ed. B. Williams, 3-21. Cambridge: Cambridge University Press 715 (1995). 716 1993. Shame and necessity. Berkeley: University of California Press. 


\section{Author Queries}

Chapter No.: 90003197158

\begin{tabular}{|c|c|c|}
\hline Queries & Details Required & Author's Response \\
\hline AU1 & $\begin{array}{l}\text { Please check and confirm if the affiliations are presented } \\
\text { correctly. }\end{array}$ & \\
\hline AU2 & $\begin{array}{l}\text { Please note that the Roman numbers "I" and "II" have been } \\
\text { set as section headings. Kindly check. }\end{array}$ & \\
\hline AU3 & $\begin{array}{l}\text { In the part "determinism comes to no more that a yes } \\
\text { answer to the question" in the extract, should "that" be } \\
\text { changed to "than"? Please check the original and confirm. }\end{array}$ & \\
\hline AU4 & Is uppercase needed for "Free Will Pessimism"? & \\
\hline AU5 & $\begin{array}{l}\text { Please check if the expression " } \beta .<\text { Exclusion Premise } \\
(E P)>\text {." Is complete. }\end{array}$ & \\
\hline AU6 & $\begin{array}{l}\text { Please check whether it is okay to delete this dash, below } \\
\text { Point } 4 .\end{array}$ & \\
\hline AU7 & $\begin{array}{l}\text { Please specify "a" and "b" for the reference "Williams } \\
(1985) \text { ". }\end{array}$ & \\
\hline AU8 & $\begin{array}{l}\text { References "Russell (2002, 2017b), Russell and Deery } \\
\text { (2013), and Watson (1982)" were not cited anywhere in the } \\
\text { text. Please provide a citation. }\end{array}$ & \\
\hline
\end{tabular}

